\title{
DATAS RADIOCARBÓNICAS DO XACEMENTO DA IDADE DO FERRO DE PENA REDONDA (PONTE CALDELAS, PONTEVEDRA).
}

\author{
ALFREDO GONZÁLEZ RUIBAL
}

\begin{abstract}
Resumo
Pena Redonda é un asentamento da Idade do Ferro atípico pola súa morfoloxía e emprazamento. Ocupouse durante a Fase I e II da Cultura Castrexa (ca. 800-100 a.C.). Durante a escavación do xacemento, en 2003, recolléronse varias amostras de carbón para a súa datación por radiocarbono, dais cais analizáronse catro. Aquí apreséntanse os resultados.
\end{abstract}

\section{Palabras chave}

Cultura Castrexa do Noroeste. Idade do Ferro. C-14.

\begin{abstract}
Pena Redonda is an atypical Iron Age settlement, for its unusual location and morphology. It was occupied during the Early and Middle Iron Age (ca. 800-100 a.C.). During the excavation of the site, in 2003, several samples of charcoal were taken for radiocarbon dating. Four samples were eventually analyzed. The results are presented here.
\end{abstract}

\section{Keywords}

Northwest of the Iberian Peninsula. Iron Age. Radiocarbon dates. 
O xacemento da Idade do Ferro de Pena Redonda (Ponte Caldelas, Pontevedra) foi obxecto de dúas campañas de sondaxes durante o ano 2003 (González Ruibal 2004, 2005) (Figura 1). A primeira campaña puxo ao descoberto dúas cabanas con varios niveis de ocupación, que cubrían a Fase I e II da Cultura Castrexa (ca. 800100 a.C.). Unha segunda intervención centrouse na liña de defensa ou delimitación, que se datou por materiais (bordes arestados ou de faceta interior) na Segunda Idade do Ferro (Fase II), e máis nunhas estruturas circulares, que resultaron ser, aparentemente, de época histórica. Durante a primeira campaña recolléronse carbóns para a súa análise radiocarbónica. As amostras foron tomadas en diversos niveis das cabanas exhumadas. A continuación ofrecemos os resultados das datacións, feitas polo laboratorio da Universidade de Uppsala e o CSIC, co financiamento do Servizo de Arqueoloxía da Xunta de Galicia ${ }^{1}$. Para a calibración das datacións utilizouse o programa OXCAL 4.01 (a última versión dispoñíbel no momento de escribir esta nota).

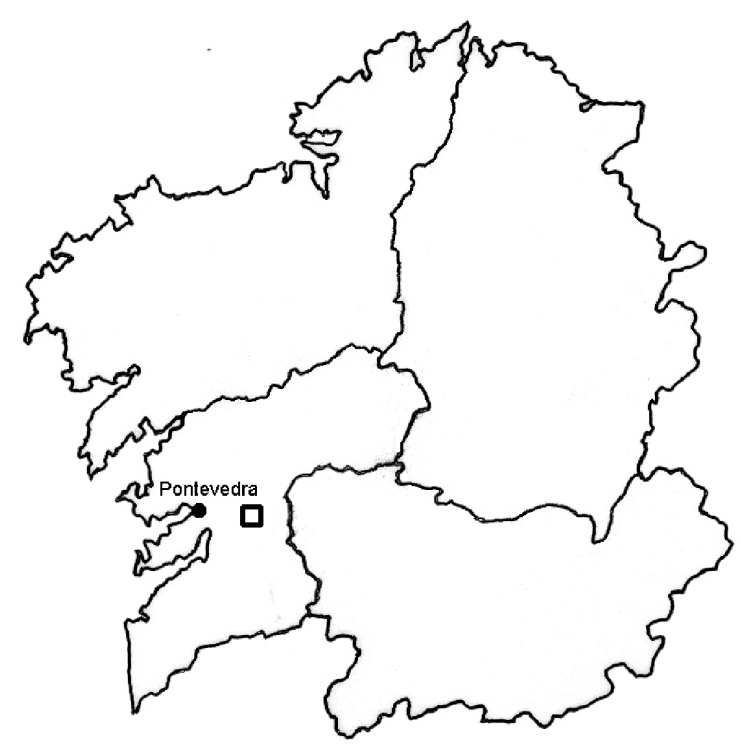

Figura 1. Ubicación do xacemento de Pena Redonda na Galiza (cadrado).

\footnotetext{
${ }^{1}$ Aproveito para agradecer a Fausto Infante (Servizo de Arqueoloxía) e Antonio Rubinos (CSIC) polas facilidades prestadas para a análise das amostras.
} 


\section{AS DATAS DA CABANA 1.}

A casa ou cabana 1 achábase moi alterada por escavacións furtivas. Só pegada a parte norte do muro circular da estrutura (UE 17) puidéronse recuperar restos de dous niveis de ocupación con moi escasos materiais. As cerámicas, non obstante, foron suficientes para datar a ocupación da estrutura de pedra e o seu pavemento nun momento indeterminado da Segunda Idade do Ferro e a ocupación anterior á súa construcción na Primeira Idade do Ferro. Os carbóns proviñan concretamente
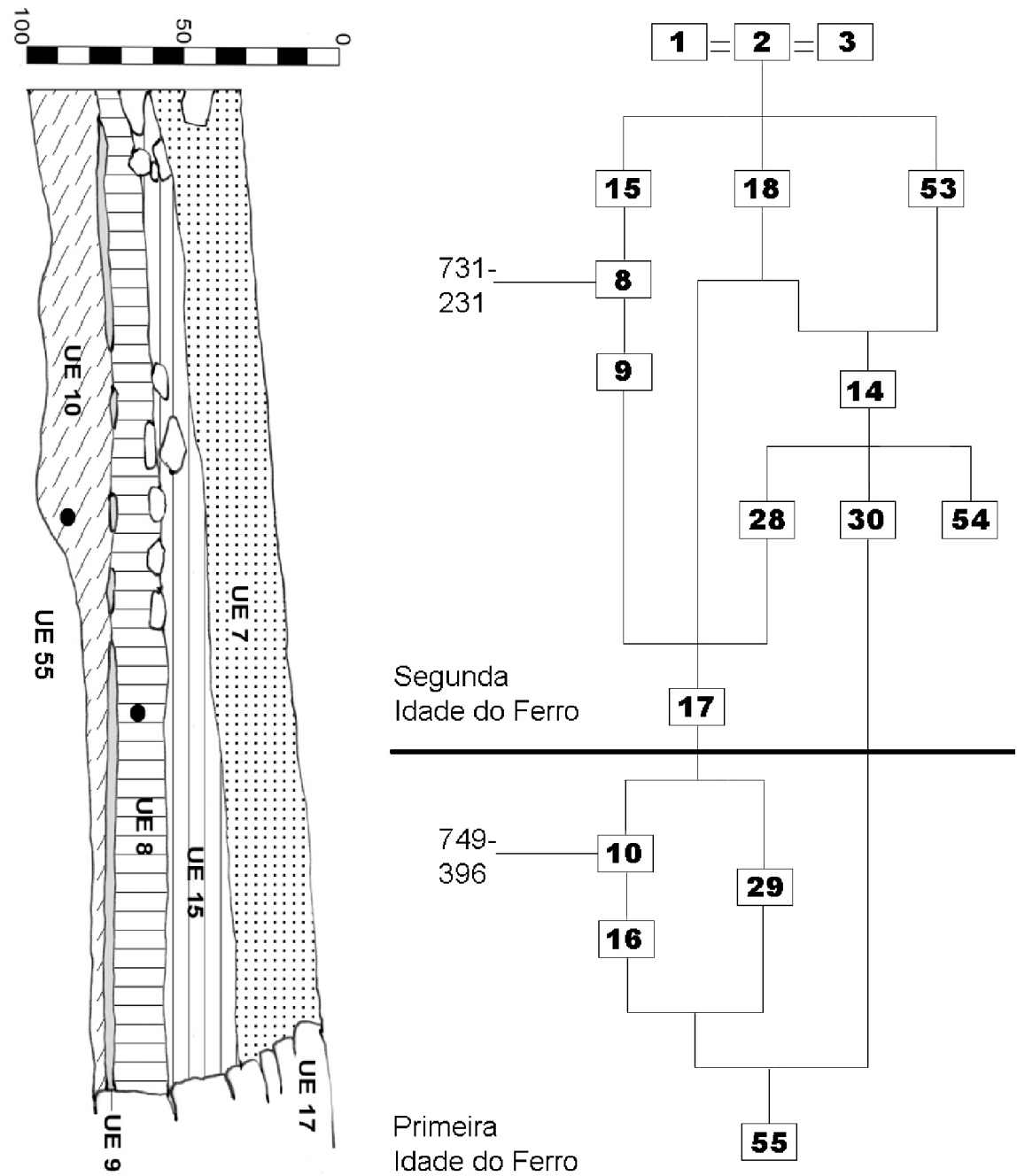

Figura 2. Estratigrafía e matriz de Harris da cabana 1, con indicación das amostras de C14 (puntos). 
da UE 8, que é o nivel de ocupación da Segunda Idade do Ferro - que cubre un pavemento de xabre (UE 9) - e da UE 10, que é un nivel do Ferro Antigo que repousa sobre a rocha nai (UE 55) e sobre unha estrutura de xabre (UE 16, seguramente
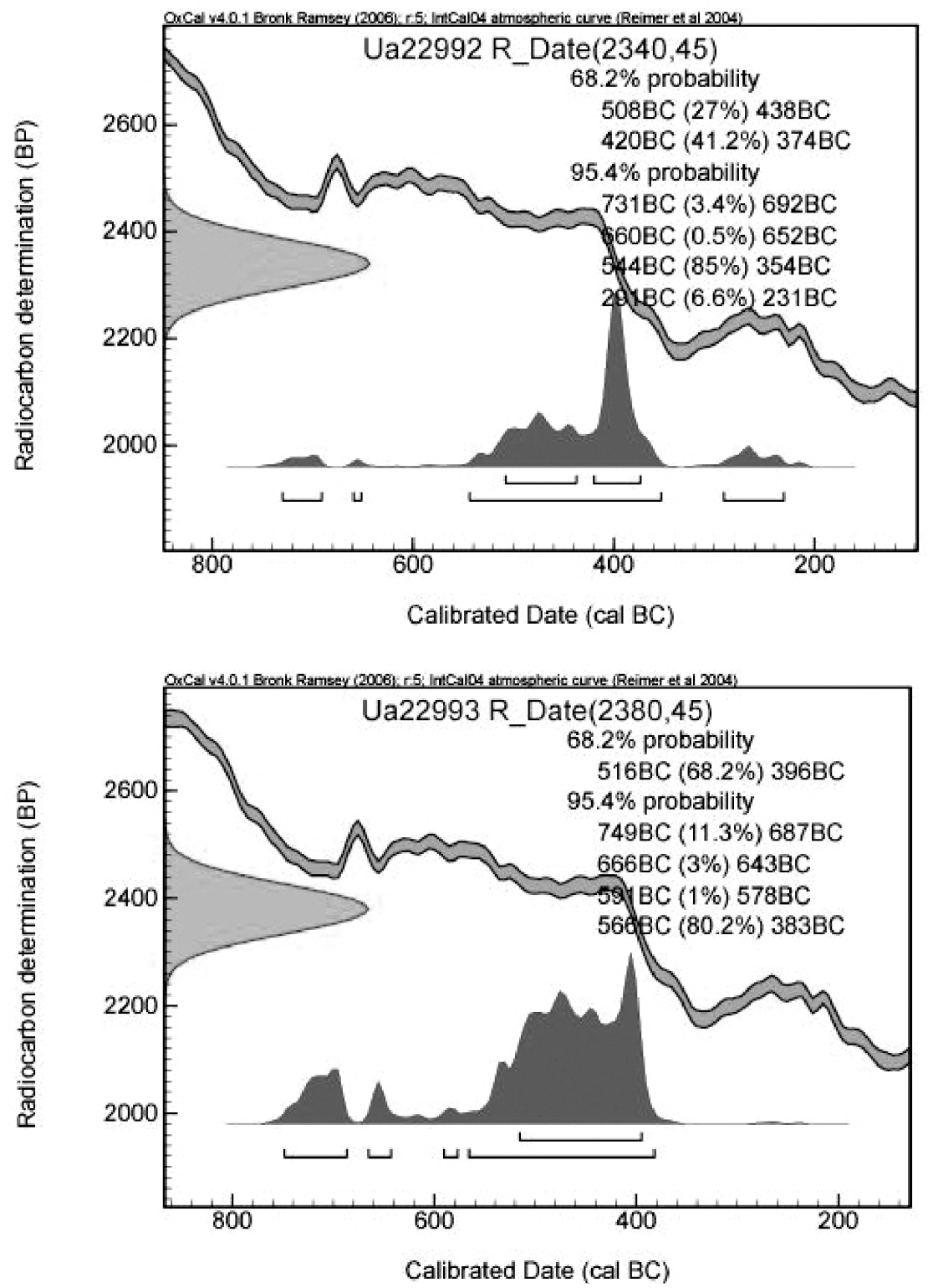

Figura 3. Gráfico das datas calibradas da cabana 1. 
restos dun fogar) (Figura 2). As datas, que tiveron que ser obtidas por AMS dada a súa escasa entidade, son as seguintes (Figura 3):

$\begin{array}{lll}\text { Ua-22992 Pena Redonda UE } 8 & -26,7 & 2340+-45 \\ 95.5 \% \text { 731-231 } & & \\ 68.2 \% \text { 508-374 } & & \\ & & \\ \text { Ua-22993 Pena Redonda UE } 10 & -25,3 & 2380+-45 \\ 95.5 \% \text { 749-383 } & & \end{array}$

$68.2 \% 516-396$

Ben que as datas resultan secuencialmente coherentes - a data da UE 8 é máis recente que a da UE 10 - o lapso temporal entre ambas é moi pequeno. O máis razoábel é considerar que ámbalas dúas amostras datan un mesmo período: o pavemento UE 9 está roto en moitos sitios (González Ruibal 2004: 20) o que sen dúbida facilitou o remexemento e desprazamento de materiais e sedimentos dun nivel para o outro (Figura 4). As raíces de toxo e fento tamén deberon facilitar estas alteracións posdeposicionais. Por outra banda, se facemos corresponder a datación radiocarbónica da UE 8 cos materiais desa UE, teríamos que considerar unha data de uso e abandono da cabana nun momento inicial da Segunda Idade do Ferro, anterior aos meados do século III a.C., o cal é incoherente cos dados que temos da cabana 2 (vid. infr.). A cabana 1 debeu ser abandonada co resto da aldea cara os finais do século II a.C. ou inicios do século seguinte. $\mathrm{O}$ borde arestado que recollimos ten os mellores paralelos en momentos avanzados do segundo Ferro (s. III-I a.C.).

Probábelmente o período no que hai que encadrar as dúas datacións sexa o final da Primeira Idade do Ferro (séculos VI-V a.C.), que sería o último momento de ocupación deste espazo antes da construcción da cabana de pedra. Calibrada a unha sigma (68.2\% de probabilidade), as dúas datas concéntranse no século $\mathrm{V}$ a.C. Isto cadraría ben cun dos escasos materiais significativos procedentes da UE 10: un borde tipo Neixón Pequeno de aspecto evoluído (González Ruibal 2004: fig. 29, UE 10). A pasta e a preparación superficial (escobillado) lembran a bordes semellantes do castro das Croas (Salcedo, Pontevedra), escavado por Antonio de la Peña (2000) ou do castro de Montealegre escavado recentemente (Aboal e Hierro 2006). Esta data resulta igualmente coherente desde un punto de vista cronolóxico con certos materiais da cabana 2 , como un borde protoarestado e máis dúas doas oculadas de pasta vítrea púnicas (González Ruibal 2004: fig. 38). En conclusión, as dúas amostras, quizáis procedentes dunha mesma bolsada de carbóns, dispersa por procesos posdeposicionais, pertencerían realmente a UE 10, que compre datar nun momento serodio da Primeira Idade do Ferro. 


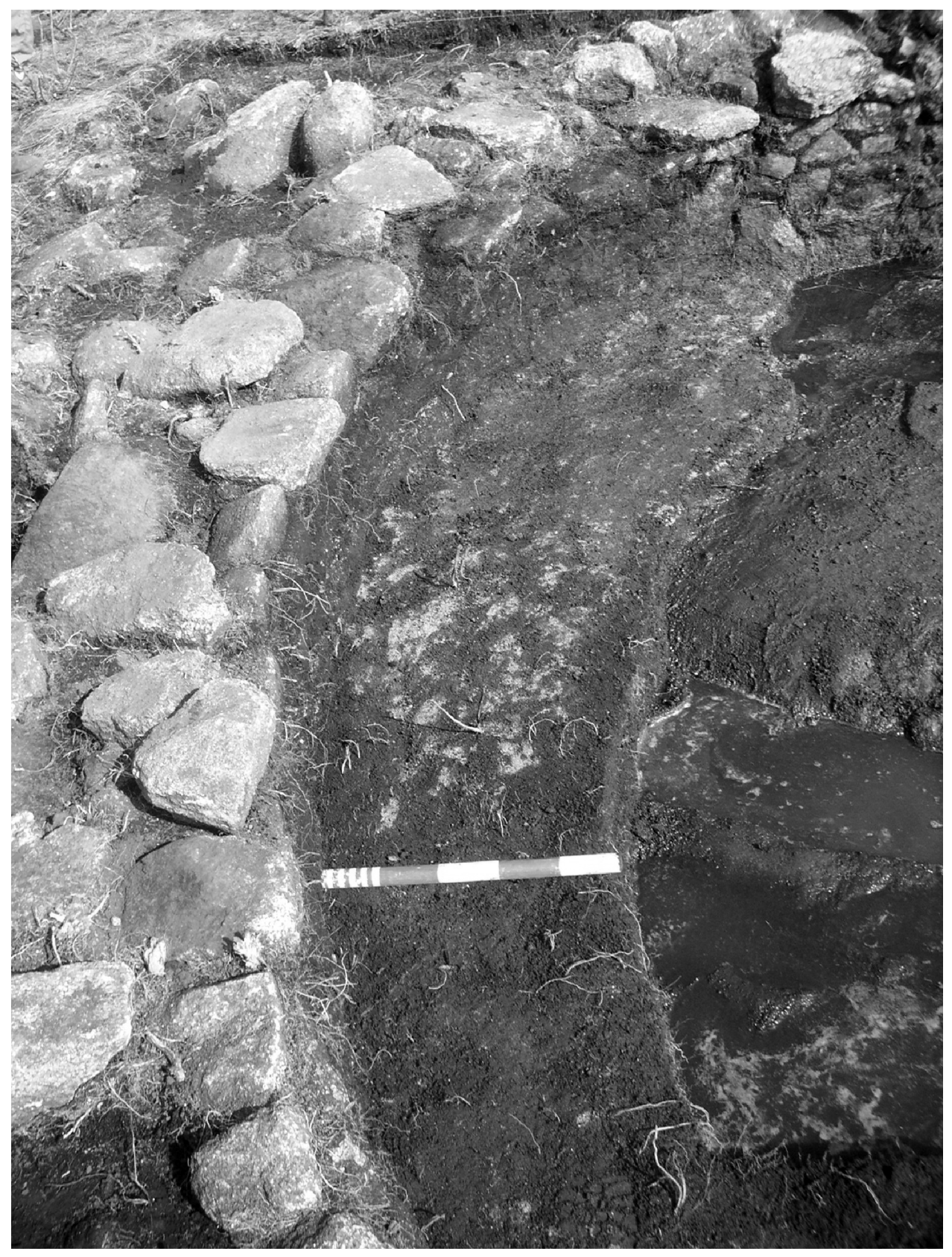

Figura 4. O pavemento (UE 9) da cabana 1, onde se aprecia claramente a súa degradación. 


\section{AS DATAS DA CABANA 2.}

A cabana 2 atopouse moi alterada por intervencións furtivas e por procesos medioambientais posteriores ao saqueo. A escavación furtiva baleirou todos os depósitos pertencentes a ocupación da cabana de pedra da Segunda Idade do Ferro, pero apenas tocou os estratos anteriores. Emporiso, a construcción desta estrutura de pedra, e máis dunha foxa, si alterou os niveis da Primeira Idade do Ferro. En total localizáronse catro niveis por debaixo da cimentación da cabana de pedra. O máis superficial, moi arrasado (UE 26), apresentaba algúns materiais característicos da Segunda Idade do Ferro, o seguinte nivel (UE 27) forneceu só materiais, moi revoltos, da Primeira Idade do Ferro. Esta camada repousaba sobre un pavemento de xabre (UE 37) e posuía un fogar conformado por dúas madeiras carbonizadas (UE 35). Por debaixo deste nivel de ocupación aínda se detectaron dous máis, un caracterizado por unha estrutura de pedra circular e outro por unha foxa curva rechea de xabre. As datacións radiocarbónicas correspóndense co penúltimo nivel de ocupación por baixo da cabana de pedra da Segunda Idade do Ferro (Figura 5 e 6):

\section{CASA 2}

Ua-22994 Pena Redonda UE 27

$-26,4$

$2120+-45$

$95.5 \% 356-4$

$68.2 \% 201-57$

CSIC-1952 Pena Redonda UE 35

$2642+-35$

95.5\% 896-776

$68.2 \% 828-795$

A primeira data, a procedente da UE 27, non se corresponde en absoluto cos materiais recuperados, adscribibeis sen nengunha dúbida ao Ferro Antigo. Compre, con todo, ter en conta unha serie de cuestións que poden explicar esta data: 1) a degradación do nivel superior conservado (UE 26), que menzoamos; 2) a escasa diferencia de cota entre as UEs 26, 27 e 35: un borde aristado característico apareceu nunha rotura do pavemento UE 26, en contacto coa UE 27;3) as alteracións producidas pola cabana de pedra da Segunda Idade do Ferro e posteriores intervencións dese período, como a foxa circular que fura os niveis do Ferro Antigo e na que apareceron materiais da Fase II (IV-II a.C.); 4) as alteracións por causas naturais dos estratos que non remexeu a intervención furtiva, pero que ficaron máis perto da superficie tras a remoción dos niveis da Segunda Idade do Ferro (Figura 7). 

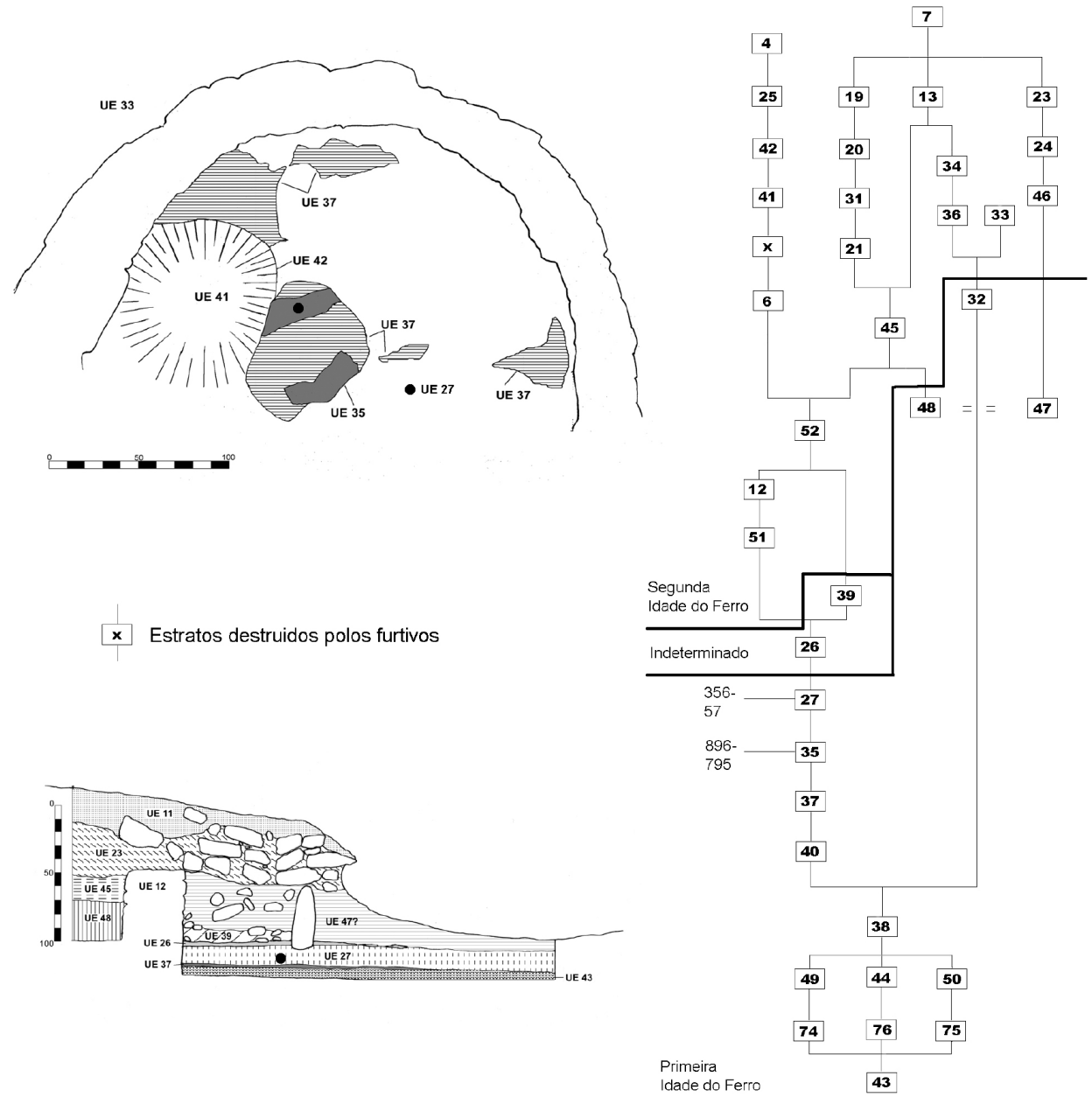

Figura 5. Planta, estratigrafía e matriz de Harris da cabana 2 con indicación das amostras de C14 (puntos).

De facto, a data resulta moi coherente coa ocupación da Segunda Idade do Ferro que coñecemos polos materiais depositados no Museo de Pontevedra. Calibrada a unha sigma, a data da UE 27 (201-57 a.C.) cadra ben co momento final de uso do asentamento que propuxen noutro lugar: finais do século II a.C. ou inicios da seguinte centuria, na transición da Fase II á III da Cultura Castrexa (González Ruibal 2004: 52; 2005: 195). É polo tanto co final da ocupación da Segunda Idade do Ferro e os seus materiais que hai que vencellar á data radiocarbónica. 

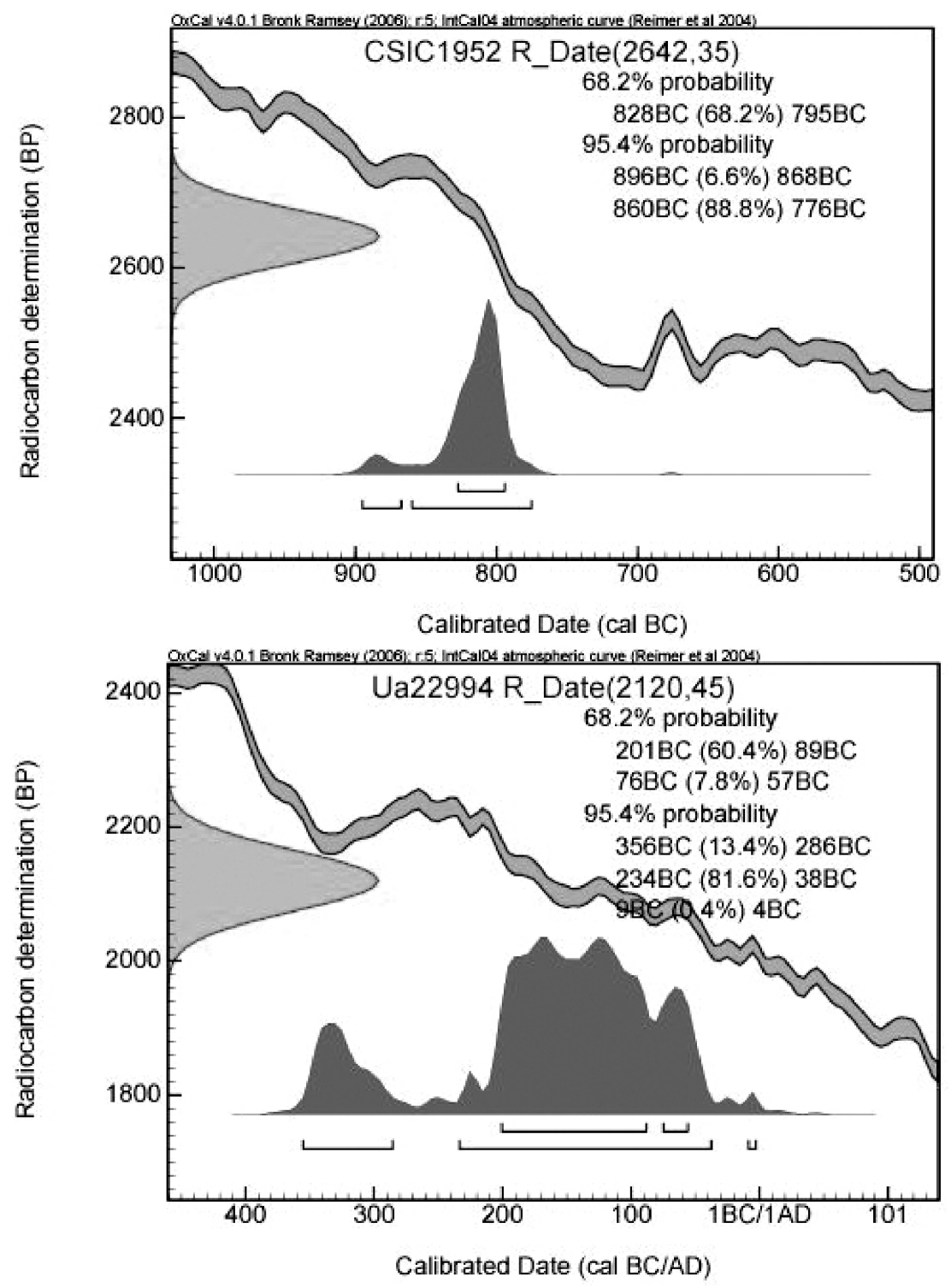

Figura 6. Gráfico das datas calibradas da cabana 2.

A outra data, procedente dun dos madeiros queimados da UE 35 (e coetánea, polo tanto, da UE 27) tamén ofrece complicacións. Se ben corrobora o encadramento da UE 27 na Primeira Idade do Ferro, o problema neste caso é que a data é antiga de máis. A miña proposta de datación para esta camada (UEs 27, 35 e 37) e 


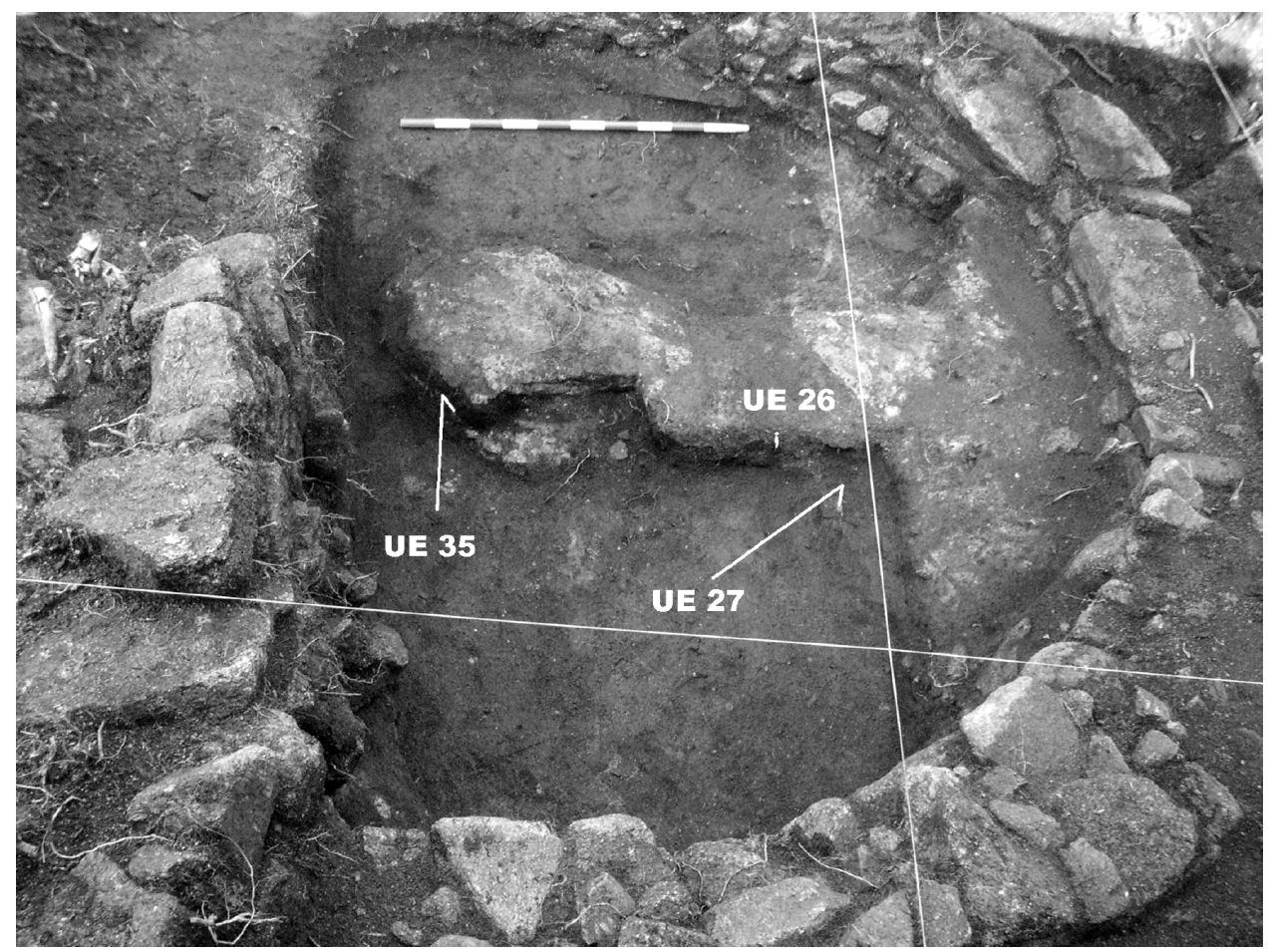

Figura 7. UEs 26, 27 e 35 da cabana 2. Obsérvase ben a proximidade de cota de todas elas e maila alteración xeral do conxunto por actuacións recentes (furtivismo) e antigas (episodios de arrasamento e construcción).

os séculos VI-V a.C., consonte a posición dentro da secuencia estratigráfica (selando varios niveis do Ferro Antigo) e os materiais recollidos - especialmente un borde protoarestado, que é frecuente en castros con niveis dos séculos VI-V a.C., como Neixón Pequeno, São Julião, Castrovite ou As Croas, pero resulta moi raro en castros máis antigos, como Torroso, onde só se recuperou un fragmento (cf. González Ruibal 2005: 191).

A data da UE 35 (2642 BP) é unha das máis antiga das publicadas polo de agora na Galiza. Inmediatamente despois atópase unha das datas de Torroso - GrN-14589 2635+-30 (Peña 1992). O castro da Graña (Melide, A Coruña) ten unha data aínda máis antiga, pero a grande desviación típica faina inválida: Gd-6074 2650+-100 (Meijide 1991). Entre as datas do castro do Achadizo (Boiro, A Coruña) hai cinco (todas elas sobre cuncha) que superan en antiguidade ás de Pena Redonda (CSIC1193 2963+-28, CSIC-1192 2789+-28, CSIC-1191 2716+-27, CSIC-1194 2706+27, CSIC-1195 2686+-28), máis non foron publicadas xunto a dados estratigráficos 
nen arqueolóxicos (Rubinos et al. 1999), o que as fai totalmente inuteis. A antiguidade da data de Pena Redonda pode explicarse pola amostra onde se obtivo: un madeiro groso carbonizado. Trataríase do "efecto madeira vella" (old wood effect), coñecido desde hai décadas (Schiffer 1986), polo cal, o que se está a datar non é o uso da madeira, senón a antiguidade do seu crecemento. Isto é especialmente problemático cando se escolle un dos aneis centrais de crecemento da madeira. No caso que nos ocupa, a trabe que se datou, ainda que de bo tamaño, achouse moi esnaquizada e remexida con terra, co que non foi posíbel distinguir o interior do exterior da madeira orixinal.

De todos xeitos, a data non desentonaría en absoluto cos niveis inferiores ás UEs 27,35 e 37 . De facto, non se pode desbotar a posibilidade de que os ocupantes dese nivel do castro reutilizaran madeira de estruturas máis antigas, un proceso que está ben testemuñado arqueolóxica e etnográficamente (Weinstein 1984; Windes e Ford 1996).

\section{CONCLUSIÓN}

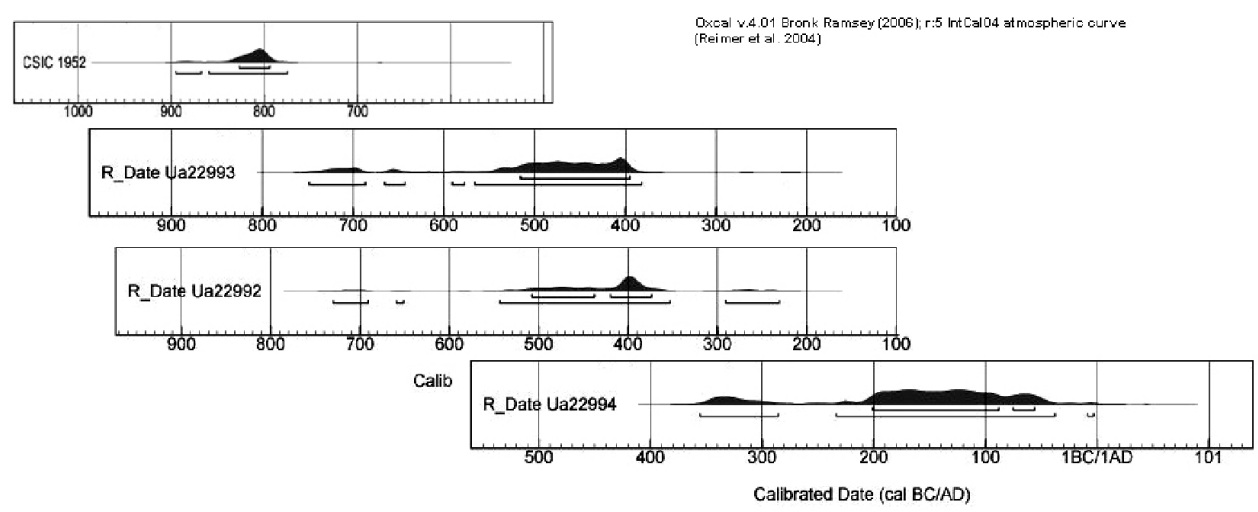

Figura 8. Datas C14 calibradas de Pena Redonda.

A pesar dos problemas que ofrecen, as datas radiocarbónicas de Pena Redonda (Figura 8) son moi coherentes co contexto estratigráfico xeral e a secuencia crono-tipolóxica do xacemento, que fica definitivamente enmarcado entre o $800 \mathrm{e}$ o 100 a.C. A maior parte dos problemas de relación entre estratos e datas pódense explicar por alteracións antrópicas ou naturais que xa foron detectadas durante a escavación. En calquera caso, nengunha data resultou anómalamente antiga nen recente. 


\section{BIBLIOGRAFÍA}

ABOAL FERNÁNDEZ, R. e CASTRO HIERRO, V., eds. 2006. O castro de Montealegre (Moaña, Pontevedra). Toxosoutos, Noia.

GONZÁLEZ RUIBAL, A. 2004. Alén dos castros: o poboado da Idade do Ferro de Pena Redonda. El Museo de Pontevedra 58: 11-63.

GONZÁLEZ RUIBAL, A. 2005. Resultado das sondaxes nun xacemento atípico da Idade do Ferro: Pena Redonda (Ponte Caldelas, Pontevedra). Cuadernos de Estudios Gallegos 52: 173-197.

MEIJIDE CAMESELLE, G. 1991. Tres dataciones de C-14 del castro de A Graña (Toques, A Coruña) y su contexto arqueológico. Gallaecia 13: 111-135.

PEÑA SANTOS, A. de la. 1992. Castro de Torroso (Mos, Pontevedra). Síntesis de las memorias de las campañas de excavaciones 1984-1990. Arqueoloxía/Memorias 11. Xunta de Galicia, A Coruña.

PEÑA SANTOS, A. de la. 2000. Castro de As Croas (Salcedo, Pontevedra). Brigantium 12. 153-160.

RUBINOS PÉREZ, A., FÁBREGAS VALCARCE, R., ALONSO MATHIAS, F., CONCHEIRO COELLO, A. 1999. Las fechas de C-14 del castro de O Achadizo (Boiro, A Coruña): Problemática de la calibración de conchas marinas. Trabajos de Prehistoria 56(1): 147-155.

SCHIFFER, M.B. 1986. Radiocarbon dating and the "old wood" problem: The case of the Hohokam chronology. Journal of Archaeological Science 13:13-30.

WEINSTEIN, J.M. 1984. Radiocarbon and some ancient Egyptian thievery. American Journal of Archaeology 88(4):591-592

WINDES, T.C. e FORD, D. 1996. The Chaco Wood Project: The chronometric reappraisal of Pueblo Bonito. American Antiquity 61(2): 295-310. 